\title{
RANCANG BANGUN SISTEM INFORMSASI PENERIMAAN SISWA BARU BERBASIS WEB (STUDI KASUS: SMK OTOMOTIF WASKITA TANGERANG)
}

\author{
Eko Sulistiyanto ${ }^{1}$ \\ ${ }^{1}$ STMIK Nusa Mandiri \\ ekosulistiyanto1@gmail.com \\ Eka W Fridayanthie ${ }^{2}$ \\ 2Universitas Bina Sarana Informatika \\ eka.ewf@bsi.ac.id \\ Maryanah Safitri ${ }^{3}$ \\ ${ }^{3}$ STMIK Nusa Mandiri \\ maryanah.msf@nusamandiri.ac.id
}

\begin{abstract}
Teknologi informasi sekarang ini telah berkembang pesat bahkan dunia pendidikan tak luput dari sentuhannya, hal ini dibuktikan dengan banyaknya sekolah mulai mengoptimalkan website untuk menyajikan informasi secara online, tetapi sekarang ini masih banyak penerimaan siswa baru dilaksanakan secara manual. Salah satu yang menjadi masalah dalam penerimaan siswa tersebut adalah membutuhkan waktu dan tenaga extra bagi panitia dalam penerimaan siswa baru. Tujuan dari penelitian ini adalah mempermudah penerimaan siswa baru dimanapun dan kapanpun secara online. Bahasa pemrograman PHP, database MySQL dan framework Codelgniter digunakan dalam pembuatan aplikasi sistem informasi penerimaan siswa baru berbasis web pada SMK OTOMOTIF WASKITA TANGERANG. Hasil dari pembuatan aplikasi sistem penerimaan siswa baru pada SMK OTOMOTIF WASKITA TANGERANG adalah penerimaan siswa baru secara online, pembayaran secara online, dan pembuatan laporan penerimaan secara online. Dengan terciptanya aplikasi ini semoga bermanfaat terhadap siswa dan membantu terhadap guru / panitia yang mengajar pada SMK OTOMOTIF WASKITA TANGERANG. .
\end{abstract}

Key Word: New Student Admission, Information Systems, Codeigniter

\begin{abstract}
Abstrak
Information technology has now developed rapidly even the education world is not spared from its touch, this is evidenced by many schools have begun to optimize web sites to provide information online, but now many are still accepting new students who are made manually. One of the problems in this admission is the need for additional time and energy for the committee in the admission of new students. The purpose of this study is to facilitate the acceptance of new students wherever and whenever online. The PHP programming language, MySQL database and Codelgniter framework are used in making web-based admission information system applications in VOCATIONAL AUTOMOTIVE VOCATIONAL SCHOOL, TANGERANG AUTOMOTIVE.The results of making a new student admission system application in VOCATIONAL SCHOOL AUTOMOTIVE VOCATIONAL SCHOOL, TANGERANG are new student admissions online, online payment, and making an online admission report. With the creation of this application, hopefully it will be useful for students and help teachers / committees who teach at VOCATIONAL SCHOOL AUTOMOTIVE VOCATIONAL SCHOOL, TANGERANG
\end{abstract}

Key Word : New student Admission, Information Sistem, Codelgnite 


\section{PENDAHULUAN}

Pada perkembangan saat ini produk teknologi yang poluler adalah teknologi website. Pada bidang pendidikan Website dimanfaatkan untuk menyajikan informasi secara online bagi aktivitas akademikanya dan masyarakat, namun sekolah juga sudah mulai mengoptimalkan website untuk dijadikan sebagai sistem online yang membantu kerja-kerja tertentu. Salah satu sistem yang sekarang terbukti manfaatnya adalah sistem informasi Penerimaan Siswa Baru (PSB) Menurut Waldopo dalam (Ningtyas, Badrul, \& Sulistyowati, 2018) mengemukakan bahwa "PPDB online atau Penerimaan Peserta Didik Baru secara online merupakan salah satu bentuk layanan penerimaan perserta didik baru berbasis TIK (Teknologi Informasi dan Komunikasi) dari Pusat Teknologi Informasi dan Komunikasi Pendidikan (Pustekkom) Kementrian Pendidikan Kebudayaan (Kemdikbud) yang diberikan secara cuma-cuma kepada seluruh Dinas Pendidikan Provinsi maupun Kabupaten/Kota yang membutuhkannya".

SMK OTOMOTIF WASKITA Tangerang, merupakan salah satu sekolah swasta di Kota Tangerang yang membuka rombongan belajar sebanyak 3 kelas, dengan kuota 100 sampai dengan 120 siswa pertahun. Dari jumlah calon siswa baru yang cukup besar ini, panitia PSB yang bertanggun jawab atas keberhasilan pemenuhan kuota siswa, membutuhkan kerja ekstra. Menurut Nugroho \& Hidayat dalam (Latifah \& Amalia, 2018) mengemukakan bahwa "Proses penerimaan siswa baru yang berlangsung secara konvesional diketahui tidak efesien, jumlah tenaga kerja yang minin dan calon siswa yang mendaftar dari luar kota, hal ini merupakan hambatan bagi proses penerimaan siswa baru"

Berdasarkan latar belakang di atas, maka penulis mempunyai gagasan penelitian yang dimaksudkan agar mempermudah perkerjaan panitia PSB yaitu "Perancangan Sistem Informasi Penerimaan Siswa Baru Berbasis Web Pada SMK OTOMOTIF WASKITA Tangerang ".

\section{Metode Penelitian}

Penulis menggunakan berberapa metode untuk mengumpulkan data dalam penelitian ini diantaranya:

\section{A. Obvervasi}

Pada tahap ini penulis melakukan pengamatan terhadap dokumen-dokumen sekolah khususnya dokumen penerimaan peserta didik baru.

\section{B. Wawancara}

Pada tahap ini penulis melakukan tanya jawab dengan para staff tata usaha mengenai semua yang berkaitan dengan proses penerimaan peserta didik baru kepada pihak SMK OTOMOTIF WASKITA Tangerang guna mendapatkan informasi yang diperlukan.

C. Studi Pustaka

Penulis melakukan studi kepustakaan untuk memperoleh aspek-aspek teoritis sebagai bahan yang mendasari pengumpulan data dan informasi, dengan membaca buku perkuliahan, jurnal serta internet dan literatur-literatur lainnya yang berhubungan dengan skripsi yang penulis buat.

\section{Hasil dan Pembahasan}

Penerimaan siswa baru berbasis web ini dirancang dengan memiliki beberapa hak akses, yaitu admin dan user. Calon siswa sebagai user dapat melakukan registrasi secara online melalui media browser internet. Panitia sebagai admin dapat melakukan konfirmasi penerimaan siswa baru secara online melalui media browser internet. Berikut ini spesifikasi kebutuhan ( system requirement ) dari sistem pendaftaran siswa baru ini ;

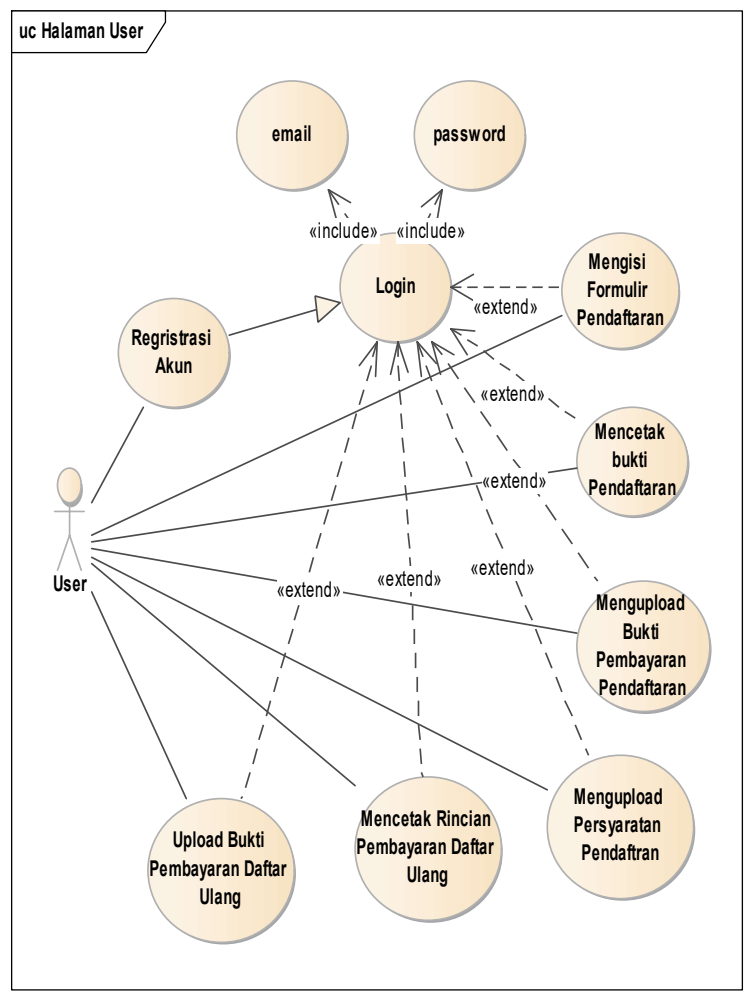

Gambar 1 Use Case Diagram Halaman User 


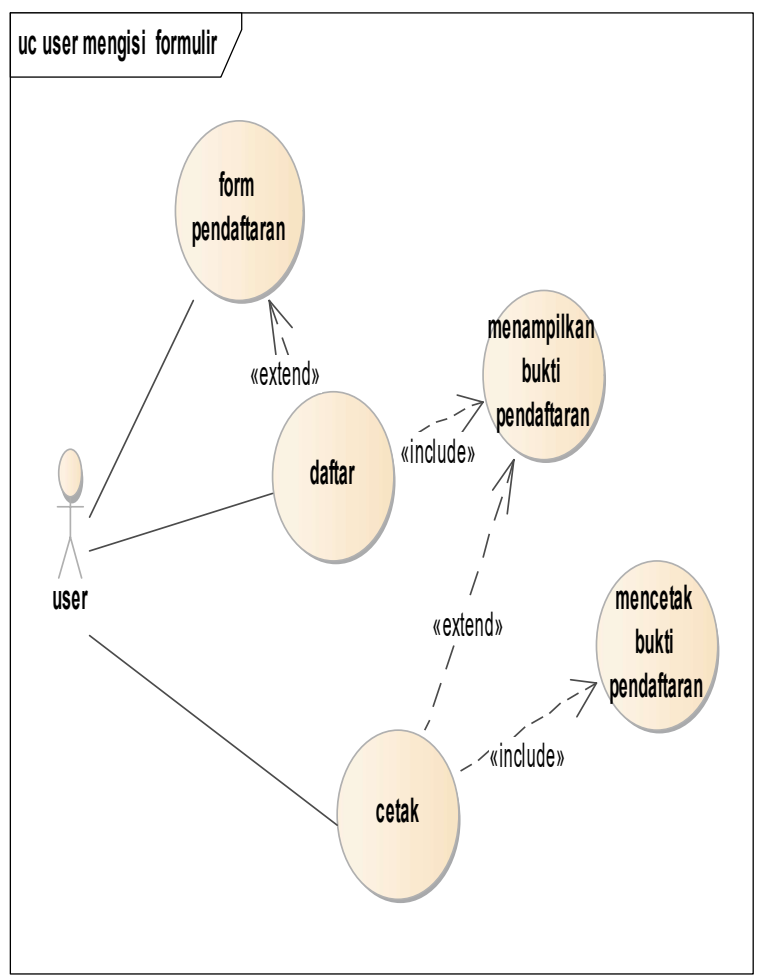

Gambar 2 Use Case Diagram Mengisi Formulir Pendaftaran

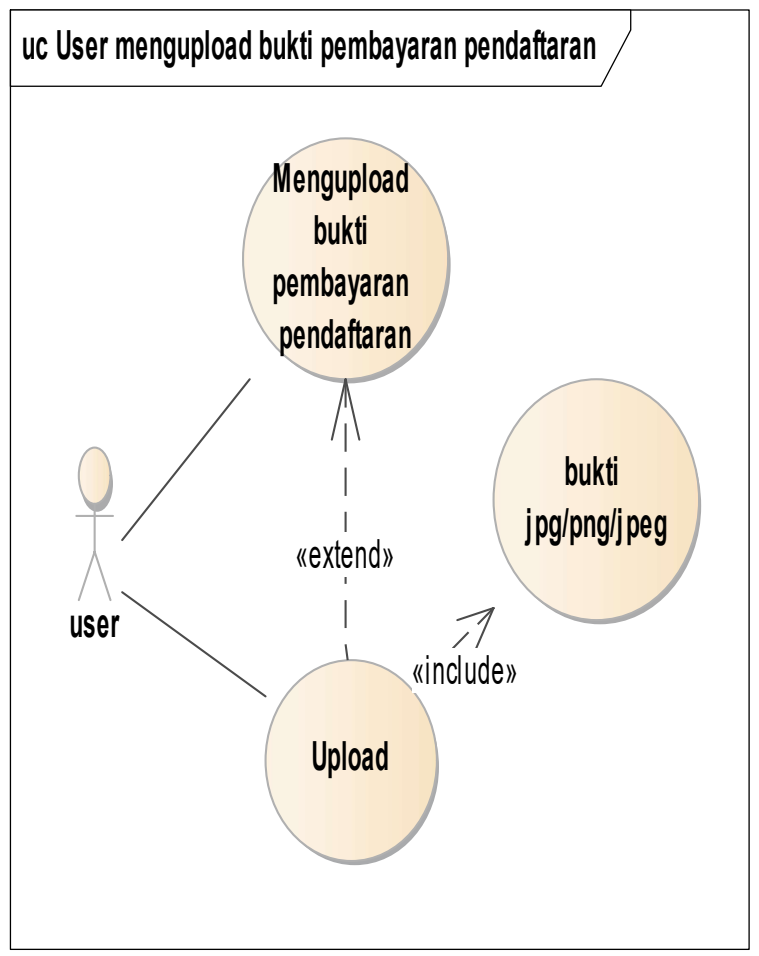

Gambar 3 Use Case

Mengupload bukti pembayaran pendaftaran

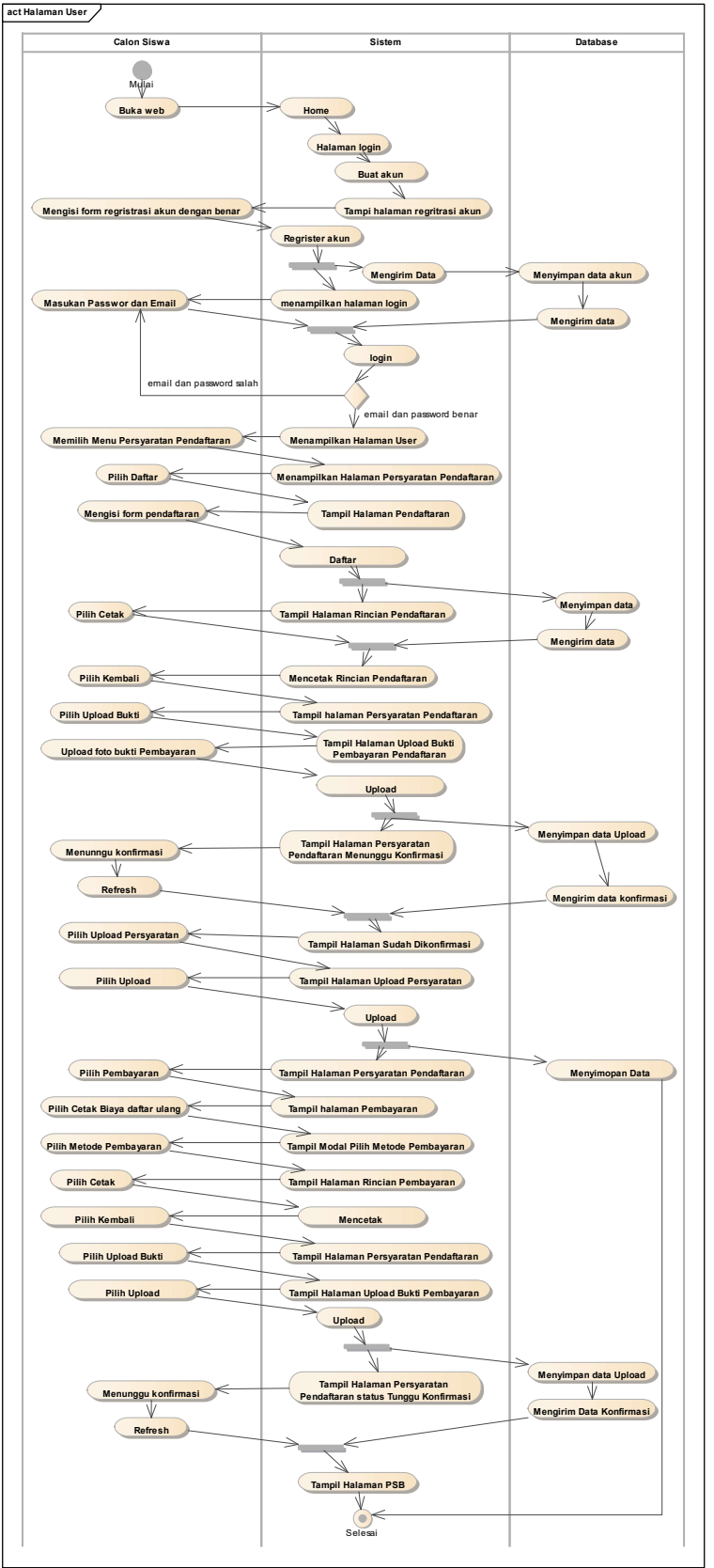

Gambar 4 Activity Diagram Halaman User

Proses desain akan menerjemahkan syarat kebutuhan kesebuah perancangan perangkat lunak yang di perkirakan sebelum dibuat coding, proses ini berfokus pada struktur data, arsitektur perangkat lunak, representasi interface dan detail (algoritma) prosedural. Dengan mengunakan UML (Unified Modelling Language) sebagai salah satu alat bantu yang sangat handal di dunia pengembangan sistem yang berorientasi obyek. Berikut penggambaran database yang digunakan dalam sistem penerimaan siswa baru berbasis web. 


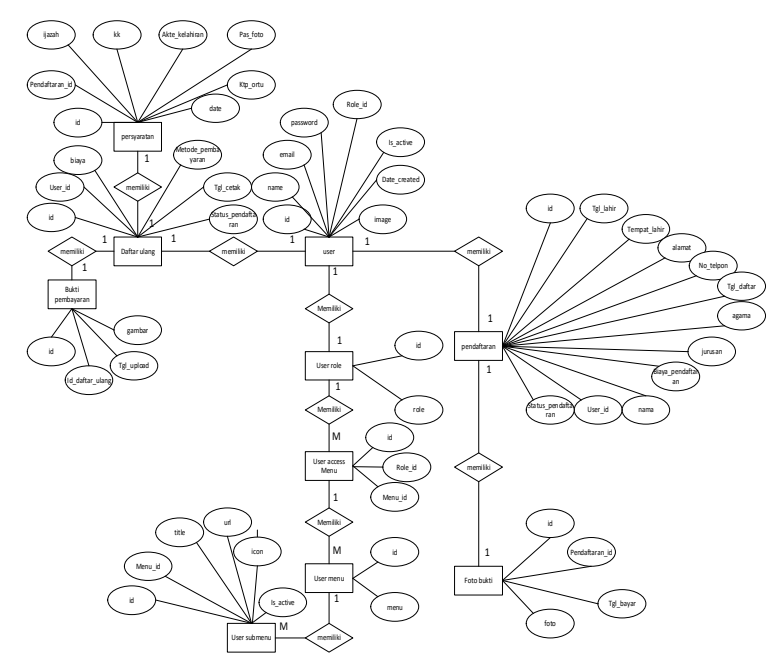

Gambar 5 ERD ( Entity Relationship Diagram ) Penerimaan Siswa Baru

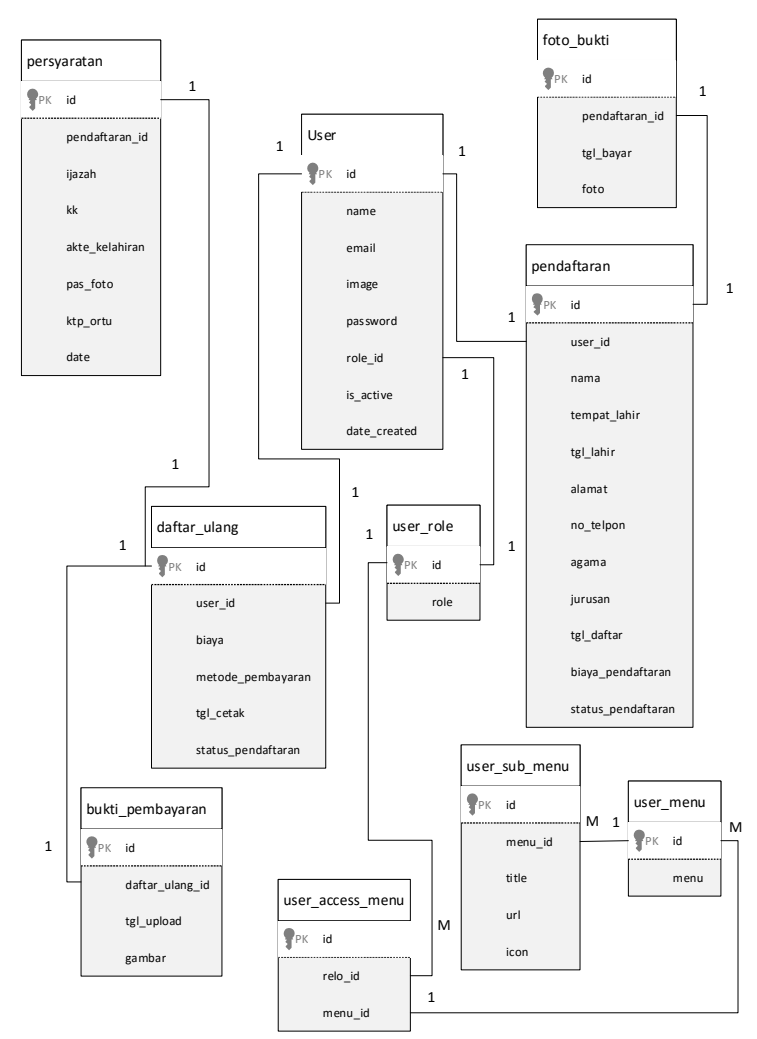

Gambar 6 Logical Record Structure Penerimaan Siswa Baru

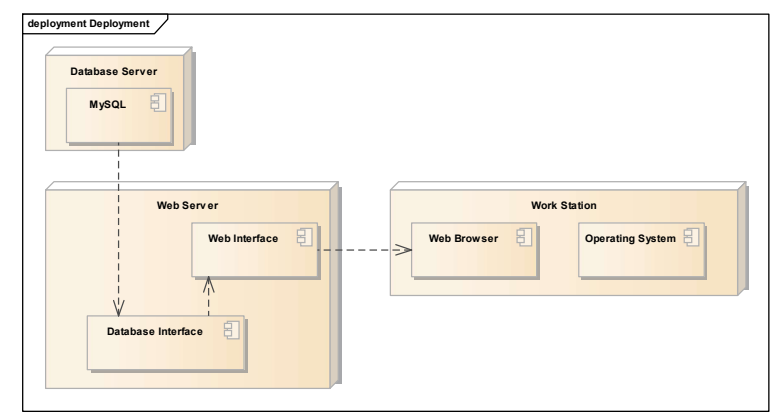

Gambar 7 Deployment Diagram Penerimaan Siswa Baru

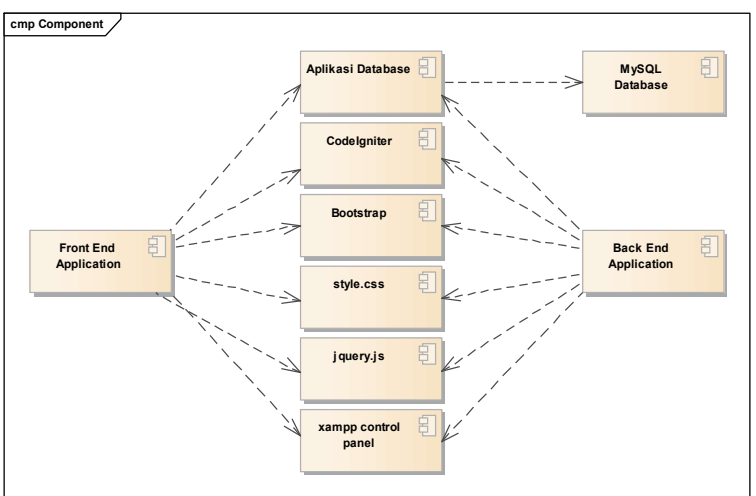

Gambar 8 Component Diagram Penerimaan Siswa Baru

\section{KESIMPULAN}

Berdasarkan hasil analisa, desain, pengkodean sampai dengan tahapan implementasi, perancangan sistem informsasi penerimaan siswa baru berbasis web pada SMK OTOMOTIF WASKITA TANGERANG ini maka penulis dapat menarik beberapa kesimpulan bahwa :

1. Dengan adanya sistem penerimaan siswa baru berbasis web ini umumnya sangat memberikan kemudahan kepada calon siswa dalam melakukan proses pendaftaran dan khususnya memudahkan pihak sekolah dalam pengolahan data dibandingkan dengan yang masih bersifat konvensional.

2. Sistem ini mampu menghasilkan informasi yang cepat, tepat dan akurat dalam menunjang proses penerimaan siswa baru.

3. Sistem ini juga dapat meminimalisir human error, kehilangan data, penumpukan penggunaan kertas sampai dengan kesalahan pendataan.

4. Dalam penggunaan framework yang dipakai dalam sistem ini yaitu menggunakan framework Codelgniter, karena framework ini ringan dan cepat dan menggunakan model MVC (Model, View, Controller) untuk membangun website dinamis dengan menggunakan bahasa PHP yang dapat mempercepat pengembang untuk membuat sebuah aplikasi web..

\section{REFERENSI}

A.S., Rosa, and M. Shalahuddin. 2015. Informatika Bandung Shalahuddin, M.Rosa A.S. Rekayasa Perangkat Lunak ( Terstruktur Dan Berorientasi Objek).

Aditiyawarman, Didih. 2016. "IMPLEMENTASI PROBLEM BASED LEARNING UNTUK MENINGKATKAN KEMAMPUAN MAHASISWA DALAM." 3(September): 
277-89.

Amin, Ruhul. 2017. "SISWA BARU PADA SMK BUDHI WARMAN 1 JAKARTA." 2(2): 113-21.

Fitriani, Eka et al. 2018. "Implementasi Model Waterfall Pada Sistem Informasi." 15(2): 137-44.

Fridayanthie, Eka W, and Jimmy Charter. 2016. "ISSN 1978-2136 | Rancang Bangun Sistem ... ISSN 1978-2136 | Rancang Bangun Sistem ..." XIII(2): 63-71.

Hendini, Ade. 2016. "PEMODELAN UML SISTEM INFORMASI MONITORING PENJUALAN DAN STOK BARANG (STUDI KASUS: DISTRO ZHEZHA PONTIANAK)." IV(2): 107-16.

Hidayat, Miwan Kurniawan, and Fachrudin Amin. 2016. "RANCANG BANGUN SISTEM INFORMASI PENERIMAAN SISWA BARU SECARA DARING PADA MAN 02 BEKASI." XVIII(2): 113-20.

Latifah, Yela, and Hilda Amalia. 2018. "Rancang Bangun Sistem Informasi Penerimaan Siswa Baru Dengan Model RAD." Perspektif XVI(2): 136-41.

Martias, Andi. 2018. "Analisa Kecukupan Penerapan Pengawasan Internal Dengan Metode System Development Life Cycle PT. XYZ." Moneter - Jurnal Akuntansi dan Keuangan 5(2): 139-48. http://ejournal.bsi.ac.id/ejurnal/index.php /moneter/article/view/3903/2693.

Ningtyas, Dwi Arum, Mohammad Badrul, and Daning Nur Sulistyowati. 2018. "Sistem Informasi Penerimaan Peserta Didik Baru Pada Smp Ar-Ridha Jakarta." Techno Nusa Mandiri Vol 15(1): No. 1. http://ejournal.nusamandiri.ac.id/ejupdfrn al/index.php/techno/article/view/744/.

Puspitasari, Diah. 2016. "SISTEM INFORMASI PERPUSTAKAAN SEKOLAH BERBASIS WEB." Advances in Engineering Software 48(1): 52-57. http://ejournal.nusamandiri.ac.id/ejurnal/i ndex.php/pilar/article/view/181/157.

Raharjo, Budi. 2015. Informatika Bandung Mudah Belajar PHP Teknik Penggunaan Fitur-
Fitur Baru Dalam PHP 5.

Sunarti. 2016. "KOPERASI HORTINA DIREKTORAT JENDERAL." 1(1) 
